\title{
Avaliação in vitro da atividade inibitória de Lactobacillus spp., isolados do inglúvio e cecos de aves sobre Salmonella
}

\author{
[In vitro evaluation of the inhibitory activity of Lactobacillus spp. isolated from crop and ceca \\ of chickens against Salmonella serotypes] \\ M.R. Barros ${ }^{1}$, R.L. Andreatti Filho ${ }^{1}$, E.T. Lima ${ }^{1}$, J.A. Crocci ${ }^{2}$ \\ ${ }^{1}$ Faculdade de Medicina Veterinária e Zootecnia - UNESP \\ Distrito de Rubião Júnior \\ 18618-000 - Botucatu, SP \\ ${ }^{2}$ Instituto de Biociências - UNESP - Botucatu, SP
}

\begin{abstract}
RESUMO
Inglúvios e cecos de reprodutoras comerciais de frangos de corte foram utilizados para o isolamento de Lactobacillus spp. As estirpes isoladas foram caracterizadas como Gram-positivo, catalase negativo, produtoras de gás em glicose, não produtoras de $\mathrm{H}_{2} \mathrm{~S}$ em triple sugar iron e identificadas pela reação em cadeia da polimerase como Lactobacillus reuteri e Lactobacillus salivarius. A utilização da técnica spoton-the-lawn para avaliação da inibição in vitro permitiu a análise de vários microrganismos simultaneamente. Todas as estirpes isoladas inibiram in vitro $S$. Enteritidis fagotipo $4, S$. Enteritidis fagotipo 28, $S$. Typhimurium, $S$. Pullorum, $S$. Agona, $S$. Anatum, $S$. Dublin e $S$. Senftenberg.
\end{abstract}

Palavras-chave: reprodutora de frango de corte, identificação, Lactobacillus, Salmonella, PCR

\begin{abstract}
Crops and ceca of commercial broiler breeders were used for the isolation of Lactobacillus spp. The isolated samples were characterized by Gram positive staining, negative catalase test, production of gas from glucose, negative for $\mathrm{H}_{2} \mathrm{~S}$ production from triple sugar iron, and were identified by the polymerase chain reaction as Lactobacillus reuteri and Lactobacillus salivarius. The use of the spot-on-the-lawn technique, with modifications, for the evaluation of the in vitro inhibition made it possible the simultaneous analysis of several microrganisms. All the crop and ceca isolated microorganisms presented an in vitro inhibitory effect against strains of Salmonella Enteritidis fagotype 4, S. Enteritidis fagotype 28, S. Typhimurium, S. Pullorum, S. Agona, S. Anatum, S. Dublin, and S. Senftenberg.
\end{abstract}

Keywords: broiler breeder, identification, Lactobacillus, Salmonella, PCR

\section{INTRODUÇÃO}

Vários gêneros e estirpes bacterianas compõem a microbiota normal do trato respiratório, inglúvio e cecos de aves, evidenciando entre essas, sempre a presença benéfica do gênero Lactobacillus spp. (Kawaguchi et al., 1991; Sarra et al., 1992), competindo contra a colonização por patógenos e, consequentemente, reduzindo a contaminação de produtos alimentares avícolas (Garriga et al., 1998).

Recebido em 21 de setembro de 2007

Aceito em 18 de maio de 2009

E-mail: merciarbpe@yahoo.com.br
Substâncias antimicrobianas como bacteriocinas, ácidos orgânicos e peróxido de hidrogênio (Cocconcelli, 1993), produzidas por bactérias presentes na microbiota intestinal, especialmente Lactobacillus spp., inibem a colonização de várias bactérias (Chaves et al., 1999) e apresentam poder de ação contra outras bactérias Gram-positivo e algumas Gram-negativo (Blackburn et al., 1989). O inglúvio e os cecos são os principais locais de colonização por Salmonella spp. em aves (Impey et al., 1984), é importante o estudo de Lactobacillus spp., 
comumente encontrados nesses segmentos e seu efeito protetor contra Salmonella spp.

Trabalhos pioneiros que relatam os efeitos benéficos de bactérias intestinais em galinhas abriram as investigações sobre o tema. Nurmi e Rantala (1973) demonstraram que a microbiota de aves adultas normais apresenta efeito protetor contra a infecção por Salmonella spp., em pintos. Miyamoto et al. (2000) investigaram Lactobacillus quantitativa e qualitativamente na cloaca e na vagina de aves e sua habilidade para inibir o crescimento de Salmonella Enteritidis. Observaram além da predominância de $L$. acidophilus, L. salivarius e L. fermentum, que Lactobacillus isolados da cloaca e da vagina também inibiram in vitro o crescimento de $S$. Enteritidis. Kizerwetter-Swida e Binek (2005) relataram que Lactobacillus inibiram in vitro bactérias enteropatogênicas como Clostridium perfringens, e o consideraram como potencial probiótico para controlar a enterite necrótica em aves.
A importância das espécies de Lactobacillus nos processos industriais ou na saúde humana e animal tem estimulado estudos de genética molecular para identificar espécies desse gênero (Chagnaud et al., 2001), e o desenvolvimento de métodos baseados na reação em cadeia da polimerase (PCR) tem aberto possibilidades para identificação precisa e rápida das bactérias acidoláticas.

Os objetivos do presente trabalho foram isolar Lactobacillus spp. do inglúvio e cecos de galinhas e avaliar a atividade inibitória in vitro contra estirpes de Salmonella.

\section{MATERIAL E MÉTODOS}

As aves utilizadas, a coleta das amostras (inglúvio e cecos), o isolamento e a identificação de Lactobacillus por meio de provas bioquímicas e da reação em cadeia da polimerase (PCR) foram apresentados por Barros et al., 2009. Os iniciadores utilizados na PCR estão descritos na Tab. 1.

Tabela 1. Iniciadores estirpe-específicos utilizados na reação em cadeia de polimerase para identificação de Lactobacillus

\begin{tabular}{llc}
\multicolumn{1}{c}{ Estirpe } & \multicolumn{1}{c}{ Iniciador $\left(5^{\prime}-3^{\prime}\right)$} & Amplicon \\
\hline L. fermentum & Fer3:ACTAACTTGACTGATCTACGA & 192pb \\
& Fer4: TTCACTGCTCAAGTAATCATC & \\
L. reuteri & Reu1: CAGACAATCTTTGATTGTTTAG & $303 \mathrm{pb}$ \\
& Reu4: GCTTGTTGGTTTGGGCTCTTC & \\
L. salivarius & Sall: AATCGCTAAACTCATAACCT & $411 \mathrm{pb}$ \\
& Sal2: CACTCTCTTTGGCTAATCTT & \\
\hline
\end{tabular}

(Song et al., 2000)

Para o multiplex PCR, realizou-se o perfil de termociclagem com os iniciadores Fer3, Fer4, Reu1, Reu4, Sall e Sal2, sendo a reação composta por tampão para PCR $1 \mathrm{x}, 2,50 \mathrm{mM}$ de cloreto de magnésio, $0,20 \mathrm{mM}$ de dNTPs, $0,4 \mu \mathrm{M}$ de cada iniciador, $1,25 \mathrm{U}$ de Taq DNA polimerase e $2 \mu \mathrm{L}$ de DNA a $0,1 \mu \mathrm{g} / \mu \mathrm{L}$ em $25 \mu \mathrm{L}$ de reação, e perfil de termociclagem $94^{\circ} \mathrm{C}-5 \mathrm{~min}$ $(1 \mathrm{x}) ; 94^{\circ} \mathrm{C}-1 \mathrm{~min}, 57^{\circ} \mathrm{C}-30 \mathrm{~s}, 72^{\circ} \mathrm{C}-1 \min (40 \mathrm{x})$; $72^{\circ} \mathrm{C}-7 \mathrm{~min}(1 \mathrm{x})$. Em seguida, o produto da PCR foi avaliado por meio de eletroforese em gel de agarose contendo $2 \%$ de brometo de etídio e marcadores de peso molecular de $50 \mathrm{pb}$ ou $100 \mathrm{pb}$.

Foram utilizadas estirpes de Salmonella $(S$. Enteritidis fagotipo 4, S. Enteritidis fagotipo 28, $S$. Typhymurium, $S$. Pullorum, $S$. Agona, $S$.
Anatum, $S$. Dublin e $S$. Senftenberg) isoladas de vísceras de galinhas, sorotipadas pelo Instituto Adolfo Lutz-SP e mantidas na bacterioteca do serviço de ornitopatologia da FMVZ- UNESPBotucatu. Cada estirpe de Salmonella mantida em ágar nutriente foi suspensa em $10 \mathrm{~mL}$ de caldo infusão cérebro coração (BHI) e incubado aerobicamente a $37^{\circ} \mathrm{C}$ por 24 horas. Após esse período, cada estirpe foi semeada em ágar verde brilhante (AVB), seguindo a mesma metodologia citada acima.

O cultivo para inibição foi realizado de acordo com a técnica spot-on-the-lawn (Lewus et al., 1991; Santos, 1993), com modificações. As estirpes de Lactobacillus foram semeadas em caldo MRS em condições de microaerofilia a 
$37^{\circ} \mathrm{C}$ por 24 horas. Após esse período, o caldo MRS foi semeado em placas de Petri contendo aproximadamente $15 \mathrm{~mL}$ de ágar MRS, mediante inoculação em pontos. Foram obtidas quatro repetições para cada estirpe, provenientes do inglúvio e cecos, com as mesmas condições de incubação citadas acima.

Concomitantemente, cada estirpe de Salmonella foi semeada em caldo BHI e incubada em aerobiose durante 12 horas a $37^{\circ} \mathrm{C}$. Foram realizadas diluições decimais seriadas para determinar a UFC/mL de cada Salmonella. Após a incubação, foram transferidos $100 \mu \mathrm{L}$ da cultura com Salmonella para tubos contendo $5 \mathrm{~mL}$ de BHI, seguida de homogeneização e transferência de $1 \mathrm{~mL}$ para novo tubo contendo $5 \mathrm{~mL}$ de BHI. Em seguida, $750 \mu \mathrm{L}$ dessa última solução foram transferidos para novo tubo contendo $15 \mathrm{~mL}$ de BHI acrescido de $0,87 \%$ de ágar ágar, previamente preparado e mantido em banhomaria a $45^{\circ} \mathrm{C}$

Cada estirpe de Salmonella acrescentada ao ágar foi dispensada sobre as placas cultivadas anteriormente com as espécies de Lactobacillus reuteri e L. salivarius provenientes do inglúvio e cecos de galinhas. Após a completa solidificação da camada superior, as placas foram incubadas a $37^{\circ} \mathrm{C}$ por 24 horas.

A inibição do crescimento de cada estirpe de Salmonella por $L$. reuteri e $L$. salivarius foi avaliada pelo diâmetro final da área de inibição, correspondendo à diferença entre o halo de inibição total e o diâmetro da colônia (Chateau et al., 1993).

Em relação ao diâmetro do halo, foi utilizada a análise de variância em blocos com aplicação do teste Tukey para comparação de médias, para estudos de: estirpes de Salmonella e segmentos (inglúvio e cecos) (ZAR, 1996).

\section{RESULTADOS E DISCUSSÃO}

As estirpes isoladas Gram-positivo, catalase negativa, produtoras de gás de glicose e não produtoras de $\mathrm{H}_{2} \mathrm{~S}$ em TSI foram consideradas como pertencentes ao gênero Lactobacillus e identificadas por meio da PCR como L reuteri e L. salivarius (Barros et al., 2009). Foram selecionadas 16 estirpes de cada espécie de Lactobacillus de acordo com o órgão de isolamento (Tab. 2), totalizando 64 amostras testadas frente às oito estirpes de Salmonella com $10^{7} \mathrm{UFC} / \mathrm{mL}$.

Tabela 2. Lactobacillus isolados do inglúvio e cecos de galinhas.

\begin{tabular}{lcr}
\hline Órgão & Lactobacillus & PCR \\
\hline Inglúvio & reuteri/salivarius & $16 / 16$ \\
Ceco & reuteri/salivarius & $16 / 16$ \\
\hline
\end{tabular}

A atividade antimicrobiana in vitro de $L$. reuteri frente às estirpes de Salmonella foi demonstrada pelos halos de inibição (Fig. 1). As medidas dos halos de inibição, promovidos por $L$. reuteri isolado de inglúvio, frente às estirpes de Salmonella não diferiram entre si. Para os isolados de cecos, as medidas dos halos de inibição para $S$. Typhimurium e $S$. Agona diferiram em relação a $S$. Anatum. Em relação a $S$. Anatum, as medidas dos halos de inibição diferiram entre os isolados de Lactobacillus de inglúvio e de ceco (Tab. 3).

L. salivarius apresentou atividade antimicrobiana in vitro frente às estirpes de Salmonella (Fig. 2). As medidas dos halos de inibição de L. salivarius isolados do inglúvio apresentaram diferença significativa para $S$. Agona e $S$. Senftenberg em relação a $S$. Dublin. Para os isolados dos cecos, as medidas dos halos de inibição contra $\mathrm{S}$. Enteritidis PT28, $S$. Agona e $S$. Senftenberg diferiram em relação a $S$. Anatum. A média de inibição para $S$. Enteritidis diferiu entre os isolados de L. salivarius de inglúvio e de cecos (Tab. 4).

A administração de microrganismos da microbiota intestinal de aves pode determinar alguma proteção de galinhas contra a colonização por alguns patógenos, como Salmonella spp. (Nurmi e Rantala, 1973; Andreatti Filho et al., 1997; 1998). 


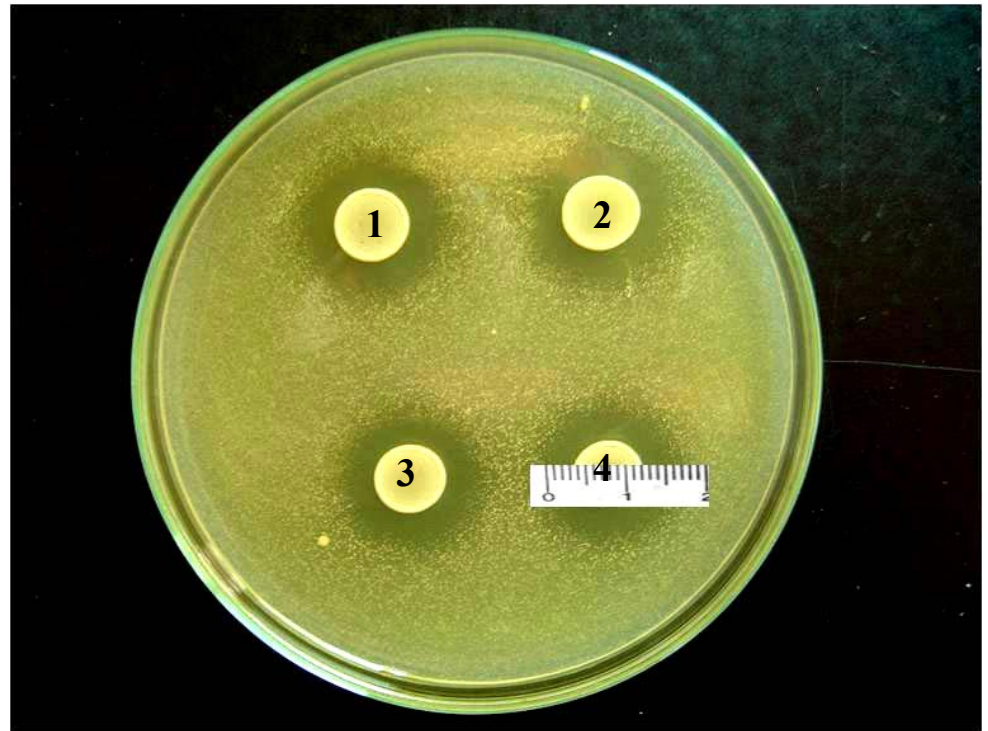

Figura 1. Atividade antimicrobiana de Lactobacillus reuteri (1, 2, 3 e 4) sobre Salmonella Pullorum, isolada de vísceras de galinhas, demonstrada pelos halos de inibição (cm) por meio da técnica spot-onthe-lawn (Lewus et al., 1991; Santos, 1993)

Tabela 3. Halos (cm) de inibição formados por Lactobacillus reuteri, isolados de inglúvio (I) e ceco (C) de galinhas, frente às estirpes de Salmonella

\begin{tabular}{ccccccccc}
\hline \multicolumn{7}{c}{ Estirpes de Salmonella } \\
\hline & Enteritidis PT4 & Enteritidis PT28 & Typhimurium & Pullorum & Agona & Anatum & Dublin & Senftenberg \\
I & $0,85 \mathrm{Aa}$ & $0,92 \mathrm{Aa}$ & $1,05 \mathrm{Aa}$ & $0,80 \mathrm{Aa}$ & $0,96 \mathrm{Aa}$ & $0,95 \mathrm{Aa}$ & $0,86 \mathrm{Aa}$ & $0,96 \mathrm{Aa}$ \\
$\mathrm{C}$ & $0,79 \mathrm{ABa}$ & $0,98 \mathrm{ABa}$ & $1,08 \mathrm{Aa}$ & $0,89 \mathrm{Aba}$ & $1,07 \mathrm{Aa}$ & $0,63 \mathrm{Bb}$ & $0,76 \mathrm{ABa}$ & $0,87 \mathrm{ABa}$ \\
\hline
\end{tabular}

Valores seguidos por letras distintas maiúsculas na linha ou minúsculas na coluna diferem entre si $(\mathrm{P}<0,05)$.

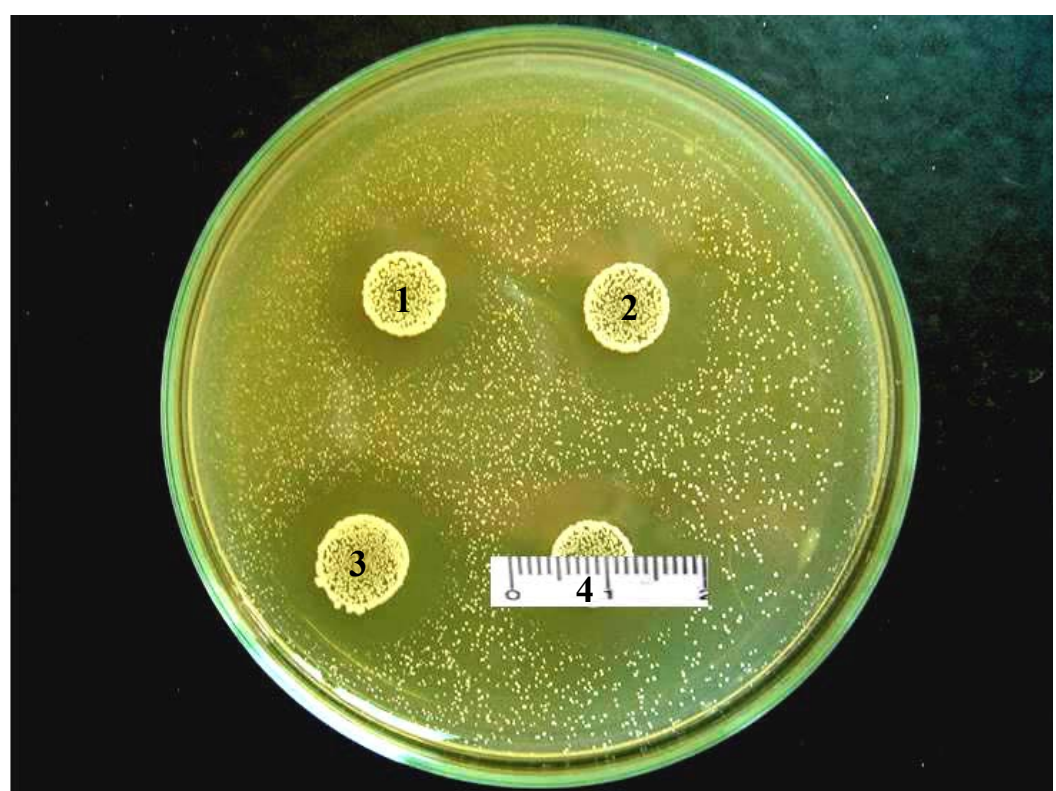

Figura 2. Atividade antimicrobiana de Lactobacillus salivarius (1, 2, 3 e 4) sobre Salmonella Typhimurium, isolada de vísceras de galinhas, demonstrada pelos halos de inibição (cm) por meio da técnica spot-on-the-lawn (Lewus et al., 1991; Santos, 1993). 
Tabela 4. Halos (cm) de inibição formados por Lactobacillus salivarius, isolados de inglúvio (I) e cecos (C) de galinhas frente às estirpes de Salmonella

\begin{tabular}{ccccccccc}
\hline \multicolumn{7}{c}{ Estirpes de Salmonella } \\
\hline & Enteritidis PT4 & Enteritidis PT28 & Typhimurium & Pullorum & Agona & Anatum & Dublin & Senftenberg \\
$\mathrm{I}$ & $0,74 \mathrm{ABa}$ & $0,80 \mathrm{ABa}$ & $0,84 \mathrm{ABa}$ & $0,80 \mathrm{ABa}$ & $1,10 \mathrm{Aa}$ & $0,86 \mathrm{ABa}$ & $0,50 \mathrm{Ba}$ & $0,90 \mathrm{Aa}$ \\
$\mathrm{C}$ & $0,94 \mathrm{ABb}$ & $1,04 \mathrm{ACb}$ & $0,92 \mathrm{ABa}$ & $0,84 \mathrm{ABa}$ & $1,02 \mathrm{ACa}$ & $0,55 \mathrm{Ba}$ & $0,60 \mathrm{BCa}$ & $1,07 \mathrm{Aa}$ \\
\hline
\end{tabular}

Valores seguidos por letras distintas maiúsculas na linha ou minúsculas na coluna diferem entre si $(\mathrm{P}<0,05)$.

Miyamoto et al. (2000) observaram, além da predominância de L. acidophilus, L. salivarius e L. fermentum, que Lactobacillus isolados da cloaca e da vagina também inibiram in vitro o crescimento de $S$. Enteritidis. Neste trabalho, $L$. salivarius do inglúvio e cecos apresentaram diferença significativa de inibição frente a $S$. Enteritidis (Tab. 4). L. reuteri, entre os isolados dos cecos, apresentou diferença significativa entre as médias dos halos de inibição referentes a $S$. Typhimurium e $S$. Agona em relação a $S$. Anatum (Tab. 3).

Chateau et al. (1993) avaliaram a atividade inibitória in vitro de $L$. fermentum, L. rhamnosus, $L$. plantarum, $L$. acidophilus e $L$. pseudoplantarum, presentes em dois probióticos, frente à Escherichia coli, Listeria monocytogenes e Salmonella. Os Lactobacillus foram mais eficientes contra as estirpes de Salmonella, sendo um dos probióticos mais eficiente contra $S$. Typhimurium, e o outro contra $S$. Enteritidis.

Considera-se importante identificar as estirpes de Lactobacillus spp., presentes no ecossistema microbiano e determinar quais apresentam efeito protetor (Song et al., 2000).

Os resultados obtidos demonstraram que todas as estirpes de $L$. reuteri e L. salivarius, provenientes do inglúvio e cecos de aves, inibiram in vitro os sorovares de Salmonella estudados ( $S$. Enteritidis fagotipo $4, S$. Enteritidis fagotipo 28, $S$. Typhimurium, $S$. Pullorum, $S$. Agona, $S$. Anatum, $S$. Dublin e $S$. Senftenberg).

A PCR foi uma ferramenta importante na identificação das amostras isoladas de aves, detectando $L$. reuteri e L. salivarius, assemelhase ao observado por Klaenhammer (1995) que, dentre as espécies de Lactobacillus em aves, estão presentes $L$. reuteri e $L$. salivarius, identificadas por meio da homologia DNA-DNA.

\section{CONCLUSÕES}

As estirpes de $L$. reuteri e $L$. salivarius isoladas do inglúvio e cecos de galinhas foram capazes de inibir in vitro $S$. Enteritidis fagotipo $4, S$. Enteritidis fagotipo $28, S$. Typhimurium, $S$. Pullorum, $S$. Agona, $S$. Anatum, $S$. Dublin e $S$. Senftenberg. A técnica spot-on-the-lawn permitiu a realização de vários testes simultaneamente. A utilização da PCR foi precisa e rápida na identificação das estirpes de Lactobacillus.

\section{AGRADECIMENTOS}

À Fundação de Amparo à Pesquisa do Estado de São Paulo (FAPESP) pelo apoio financeiro.

\section{REFERÊNCIAS BIBLIOGRÁFICAS}

ANDREATTI FILHO, R.L.; SILVA, E.N.; CURI, P.R. Ácidos orgânicos e microbiota cecal anaeróbica no controle da infecção experimental de frangos por Salmonella typhimurium e Salmonella enteritidis. Arq. Bras. Med. Vet. Zootec., v.49, p.661-672, 1997.

ANDREATTI FILHO, R.L.; SILVA, E.N.; CURI, P.R. Control of experimental infection of broilers by Salmonella Enteritidis and $S$. Typhimurium with the use of organic composites and anaerobic cecal microflora. In: INTERNATIONAL SYMPOSIUM ON FOODBORNE SALMONELLA IN POULTRY, 1998, Baltimore. Proceedings... Baltimore: American Association of Avian Pathology, 1998.

BARROS, M.R.; ANDREATTI FILHO, R.L.; OLIVEIRA, D.E. et al. Comparação entre método bioquímico e reação em cadeia da polimerase para identificação Lactobacillus spp. isolados de aves. Arq. Bras. Med. Vet. Zootec., v.61, p.319-325, 2009. 
BLACKBURN, P.; POLAK, J.; GUSIK, S.A. et al. Nisin Composition for use as enhaced broad range bactericids. International Patent Aplication n. PCT/US89/02625; Int. Publ. WO89/12399. New York: Applied Microbiology, 1989.

CHAGNAUD, P.; MACHINIS, K.; COUTTE, L.A. et al. Rapid PCR-based procedure to identify lactic acid bacteria: application to six common Lactobacillus species. J. Microbiol. Methods, v.44, p.139-48, 2001.

CHATEAU, N.; CASTELLANOS, I.; DESCHAMIS, A.M. Distribuition of pathogen inhibition in the Lactobacillus isolation of a commercial probiotic consortium. J. Appl. Bacteriol., v.74, p.36-40, 1993.

CHAVES, A.H.; SILVA, J.F.C.; PINHEIRO, A. et al. Isolamento de Lactobacillus acidophillus a partir de fezes de bezerros. Rev. Bras. Zootec., v.28, p.1086-92, 1999.

COCCONCELLI, P.S. Aspetti molecular de batteriocine prodolte da Lactobacillus Ann. Microbiol. Enzimol., v.43, p.37-44, 1993.

GARRIGA, M.; PASCUAL, M.; MONFORT, J.M. et al. Selection of Lactobacilli for chicken probiotic adjunts. J. Appl. Microbiol., v.84, p.125-132, 1998.

IMPEY, C.S.; MEAD, G.C.; GEORGE, S.M. Evaluation of treatment with defined and undefined mixture of gut microorganisms for preventing Salmonella colonization in chicks and turkey poults. Food. Microbiol., v.1, p.143-147, 1984.

KAWAGUCHI, I.; HAYASHIDANI, H.; KANEKO, K. et al. Bacterial flora of the respiratory tracts in chickens with a particular reference to Lactobacillus species. J. Vet. Med. Sci., v.54, p.261-267, 1991.
KIZERWETT-SWIDA, M.; BINEK, M. Selection of potentially probiotic Lactobacillus strains towards their inhibitory activity against poultry enteropathogenic bacteria. Pol. $J$ Microbiol.,v. 54, p.287-94, 2005.

KLAENHAMMER, T.R. Genetics of intestinal lactobacilli. Int. Dairy J., v.5, p.1019-1058, 1995.

LEWUS, C.B.; KAISER, A.; MONTIVILLE, T.J. Inhibition of Food-Borne Bacterial Pathogens by Bacteriocins from Lactic Acid Bacteria Isolated from Meat. Appl. Environ. Microbiol., v.57, p.1683-1688, 1991.

MIYAMOTO, T.; HORIE, T., FUJIWARA, T. et al. Lactobacillus flora in the cloaca and vagina of hens and its inhibitory activity against Salmonella Enteritidis In vitro. Poult. Sci., v.79, p.7-11, 2000.

NURMI, E.; RANTALA, M. New aspects of Salmonella infection in broiler production. Nature, v.241, p.210-211, 1973.

SANTOS, W.L.M. Aislamiento y caracterizacion parcial de una bacteriocina producida por Pediococcus sp. 347, de origem carnico. 1993. 294f. Tese (Doutorado) - Universidade Complutense de Madrid, Madrid.

SARRA, P.G.; MORELLI, L.; BOTTAZZI, V. The lactic acid microflora of fowl. In: WOOD, B.J.B. (Ed). The lactic acid bacteria in health and diseases. London: Elsevier, 1992. p.3-19.

SONG, Y.L.; KATO, N.; LIU, C.X. et al. Rapid identification of 11 human intestinal Lactobacillus species by multiplex PCR assays using group and species-specific primers derived from the 16S-23S rRNA intergenic spacer region and its flanking 23S rRNA. FEMS. Microbiol. Lett., v.187, p.167-173, 2000.

ZAR, J.H. Biostatistical analysis. New Jersey: Prentice Hall, 1996. 718p. 